Mandibular 1.

ve 2. büyük azı

dişlerinin mezial

köklerindeki isthmus

tipi ve oranlarının

değerlendirilmesi:

histolojik yöntem

\section{Evaluation of the incidence and type of isthmus in mesial root canals of mandibular first and second molar teeth: a histological method}

\author{
Dr. Güher Barut \\ Yeditepe Üniversitesi Diş Hekimliği Fakültesi Endodonti \\ Anabilim Dalı, Istanbul
}

Prof. Dr. Faruk Haznedaroğlu

Isstanbul Üniversitesi Diş Hekimliği Fakültesi Endodonti Anabilim Dalı, İstanbul

Geliş Tarihi : 17 Kasım 2015

Kabul Tarihi : 22 Şubat 2016

\author{
Yazışma adresi: \\ Dr. Güher Barut \\ Yeditepe Üniversitesi Diş Hekimliği Fakültesi Endodont \\ Anabilim Dalı \\ Bağdat Caddesi No:238 Göztepe Istanbul \\ E-mail: guherbarut85@hotmail.com \\ Tel: 021636360 44-6466
}

ÖZET

Amaç: Bu çalışmanın amacı, mandibular 1. ve 2. büyük azı dişlerinin mezial köklerindeki isthmus tipi ve oranlarının kuronal, orta ve apikal bölümlerinden alınan histolojik kesitler üzerinde değerlendirilmesidir.

Gereç ve Yöntem: 100 adet çekilmiş mandibular 1. ve 2. büyük azı dişlerinin mezial kökleri kullanıımıştır. Kök ucu gelişimi tamamlanmış, kırık, çatlak olmayan ve kanal tedavisi girişiminde bulunulmamış dişler çalışmaya dahil edilmiştir. Distal köklerinden ayrılan mezial kökler kullanım zamanına kadar \%10'luk formalin içinde bekletilmiştir. Örnekler kuronal, orta ve apikal bölgelere ayrlarak parafin bloklara gömülmüştür. Hematoksilen-eozin ile boyanan toplamda 30 adet kesit görüntüsü ışı mikroskobunda x40 büyütme altında incelenmiştir. İsthmus sınıflaması Hsu \& Kim'e göre yapıımışı̆r. Verilerin değerlendirilmesinde Kruskal Wallis testi kullanılmıştır. Sonuçlar, anlamlılı $p<0,05$ düzeyinde değerlendirilmiştir

Bulgular: Mezial köklerde isthmus görülme oranları kuronal bölgede \%86, orta bölgede \%72 ve apikal bölgede \%84'tür. En sık karşlaşılan isthmus tipi ise kuronalde \%70, ortada \%56 ve apikalde \%62 oranı ile tip $\vee$ olarak tespit edilmiştir $(p<0.05)$.

Sonuç: Alt molar dişlerin mezial köklerinde gerçekleştirdiğimiz çalışmamızda isthmus görülme sıkl|ğının çok yüksek olduğu saptanmıştır. İsthmus varı̆ı̆ı dikkate alındığında, bu alanlara yönelik etkin yıkama ve şekilllendirme yöntemleri ile kök kanal tedavisi başarısı arasındaki ilişkinin önemi daha iyi anlaşılmaktadır.

Anahtar Kelimeler: Isthmus, mandibular büyük azı, mezial kök, kanal morfolojisi, histolojik

\section{SUMMARY}

Aim: The aim of this study is to investigate ex vivo the incidence and type of root canal isthmuses in the coronal, middle and apical part of the mesial root of mandibular first and second molars by histological sections.

Materials and methods: One hundred extracted mesial roots of human mandibular first and second molars with mature roots were selected. The mesial roots were sectioned from the distal roots and were kept in 10\% formalin until use. The roots were demineralized in 10\% formic acid for 28 days. The coronal, middle and apical thirds of the decalcified roots were dissected and embedded in paraffin. A total of thirty semi-serial sections of each root were mounted on glass slabs, stained with hematoxylin eosin and examined under an optical microscope at $\times 40$ magnification. The evaluation of the incidence and types of isthmus was based on the classification by Hsu \& Kim. All data were statistically analyzed by the Kruskal-Wallis test. The statistical significance level was established at 0.05. 
Results: The incidence of isthmus in mesial roots were $86 \%$ in coronal, $72 \%$ in middle and $84 \%$ in apical regions ( $p<0.05$ ) The most prevalent isthmus type in coronal (70\%), middle (56\%) and apical (62\%) parts was type $V(p<0.05)$.

Conclusion: The incidence of root canal isthmus in mesial root of mandibular first and second molars is high Therefore, cleaning and shaping of these isthmuses are a major challenge during root canal treatment.

Keywords: Isthmus, mandibular molar, mesial root, canal morphology, histological

\section{GíRiș}

Kök kanallarındaki kimyasal ve mekanik hazırlığın amac kök kanal sisteminde yeterli temizliği sağlamaktır. Kök kanal tedavisinin başarısında kanal morfolojisinin önemli bir rol oynadığı bilinmektedir. Kök kanal sisteminde, ana kanalın yanı sıra aksesuar, lateral ve C-şekilli kanallar, isthmus alanları, özellikle kök ucunda delta ve dallanmalar, kanallar arası bağlantıların varığı bir çok araştırmacı tarafından bildirilmiştir1, 2, 3. Kök kanal anatomisinin karmaşık yapısı sebebiyle mekanik temizliğin yeterli olmadığı, bu yapıların bakteri ve nekrotik pulpa dokuları için rezervuar görev yaparak endodontik tedavi başarısızlığından sorumlu olduğu bilinmektedir ${ }^{4}, 5$. Alt molar dişler sıklıkla tedavi edilen diş grubu olmakla birlikte kök kanal konfigürasyonlarının en sık karşılaşıldığı dişlerdir?

Kök kanalı konfigürasyonlarını inceleyen çalışmalarda polyester reçine ölçüler, şeffaflaştırma ve radyografi gibi metodlar kullanıımışır.2,-10 Literatürde bu metodların yanı sira, micro-computed tomografi (mCT) ${ }^{11}$ ve cone-beam computed tomografi (CBCT)12,13 kullanılan çalışmalar da bulunmaktadır.

Weine ve ark. ${ }^{14}$ Pineda \& Kuttler $^{15}$ ve Vertucci ${ }^{2}$ gibi araştırmacılar kök kanallarında var olan isthmus ve kanal konfigürasyonları için sınıflamalar geliştirmişlerdir Vertucci'nin kendi adıyla anılan sınıflaması sıklıkla kullanılan ve en çok bilinen sınıflamalardan biridir. Bu araştırmacıların yanı sıra Hsu \& Kim'in ${ }^{16}$ yapmış olduğu sınıflama da isthmus tiplerinin incelendiği birçok çalışmada kullanılmışıı177-19.

Bu çalışmanın amacı, mandibular molar dişlerin mezial köklerindeki isthmus tipi ve oranlarının kuronal, orta ve apikal bölümlerinden alınan histolojik kesitler üzerinde değerlendirilmesidir.

\section{GEREÇ VE YÖNTEM}

Bu çalışma, İstanbul Üniversitesi Diş Hekimliği Fakültesi Endodonti Anabilim Dalı Kliniği ve I.Ü.Tıp Fakültesi Onkoloji Enstitüsü Patoloji bölümünde gerçekleştrilmiştir Çalışmaya başlamadan önce I.Ü. Tıp Fakültesi Etik Kurulu'na başvurulmuştur. Başvuru sonucunda, 13.10.2014 tarih ve 21 sayı numarası ile onay alınmıştır.

\section{Örnek Dişlerin Seçimi}

Çalışmamızda, çekim nedenleri bilinmeyen 100 adet insan alt 1. ve 2. büyük azı dişi kullanıımıştır. Kullanılacak örnek dişlerin mezial kökleri, hem görsel hem de radyografik olarak incelenmiştir. Buamaçla, bukko-lingualvemezio-distalyönde dijital radyografiler alınmışırı (Kodak 2100 Rvg, Rochester NY, USA). Bukko-lingual yönde alınan radyografiler üzerinde, ImageJ Software (National Institutes of Health, Bethesda, MD, USA) programı yardımıyla Schneider tekniğine göre kök eğimleri saptanmıştır. Bu veriler ışığında örnek dişlerin radyolojik değerlendirmesi sonucunda; kök eğimlerinin $10^{\circ}$ $25^{\circ}$ aralığında bulunan, tek foramende sonlanan (Weine tip II) iki ayrı kök kanalına sahip olan örnekler dahil edilmiştir Yapılan görsel değerlendirmede ise, kök gelişiminin tamamlanmış olmasına ve rezorpsiyon, çürük, çatlak ve kırık gibi nedenlerle kök bütünlüğünün bozulmamış olmasına dikkat edilmiştir. Kalsifikasyon, iç rezorpsiyon gibi patolojiye sahip olan veya daha önceden kök kanal tedavisi girişimi olan dişler çalışmaya dahil edilmemiştir.

\section{Örnek Dişlerin Hazırlanması}

Çalışmada kullanılacak dişler üzerindeki yumuşak doku artıkları bisturi yardımıyla uzaklaş̧ıııımış, diş taşı ve sert doku artıkları da scaler yardımıyla temizlendikten sonra, seçilen örnek dişlerin mezial kökleri, boyları kök ucundan itibaren 12 mm olacak şekilde, aeratöre takılan 014 numaralı bir alev uçlu frez (Jota, Swiss) yardımıyla su soğutması alında kesilerek ayrılmıştır. Örnek dişler, pulpa fiksasyonunun sağlanması için kullanılacakları zamana kadar \% 10 formalin çözeltisinde, 8 hafta süreyle saklanmıştır.

\section{Histolojik Değerlendirme}

Fiksasyon işleminden sonra, örnek dişler dekalsifikasyon amacıyla içinde $40 \mathrm{ml}$ \% 10 formik asit bulunan plastik tüplere konmuş ve oda sıcaklı̆ında dört hafta süreyle bekletilmiştir Dekalsifiye olan örnek dişler, kuronal, orta ve apikal olarak 3 bölgeye ayrilarak doku takip kasetleri içine alınmıştır 
Sonrasında ise 12 saat boyunca doku takip cihazında işleme tabi tutulmuştur. Parafine alınan örneklerden mikrotom (Leica Biosystems, Germany) kullanılarak her bir bölgeden 10 adet olmak üzere 3-5 mikron kalınlığında kesitler alınmıştır. Lamlar üzerine alınan kesitler hematoksilen-eozin ile boyanmıştır. Daha sonra, ışık mikroskobunda (Olympus BX60, Japan) x40 büyütme altında incelenmek üzere bir örneğin apikal, orta ve kuronal olmak üzere her bölgesinden 10 adet olmak üzere toplamda 30 adet kesit seçilmiştir. Seçilen kesitlerden alınan dijital görüntüler kodlanmış ve bilgisayar ortamına taşınmıştır. Görüntüler Adobe Photoshop CS4 Extended (Adobe Systems Inc, San Jose, California) yardımıyla birleştirilmiştir. Elde edilen görüntüler tek bir araştııı I tarafindan incelenmiş olup, isthmus sınıllaması Hsu \& Kim ${ }^{16}$ e göre yapılmıştır. Buna göre:

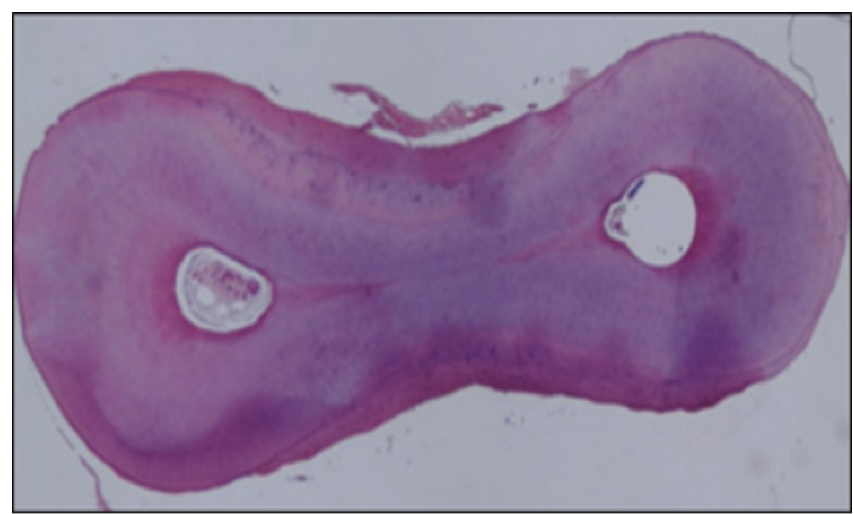

Resim 1: Çalışmamızda kullandığımız örnek dişler arasında Tip I isthmus varlığı

Tip l: Aralarında bir bağlantı olmaksızın iki kanal varlığı (Resim 1)

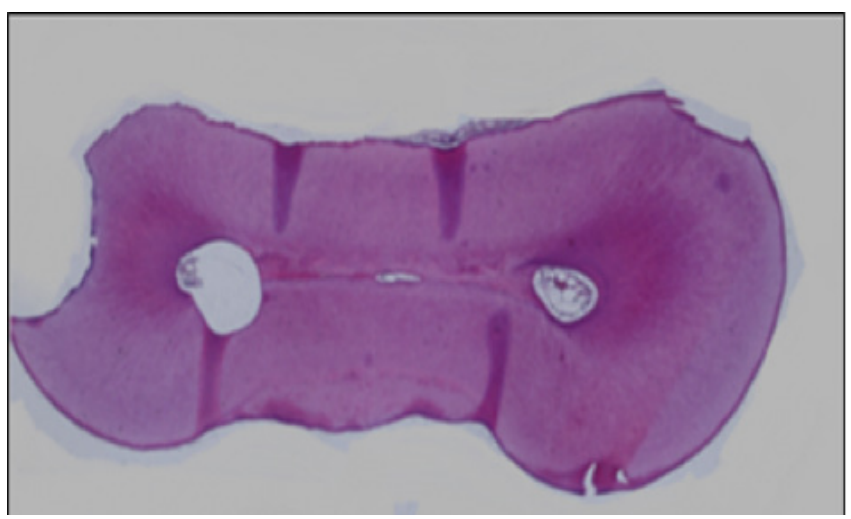

Resim 2: Çalışmamızda kullandığımız örnek dişler arasında Tip II isthmus varlığı

Tip II: Aralarında farkedilebilir derecede bir bağlantı olan iki kanal varlığı (Resim 2)

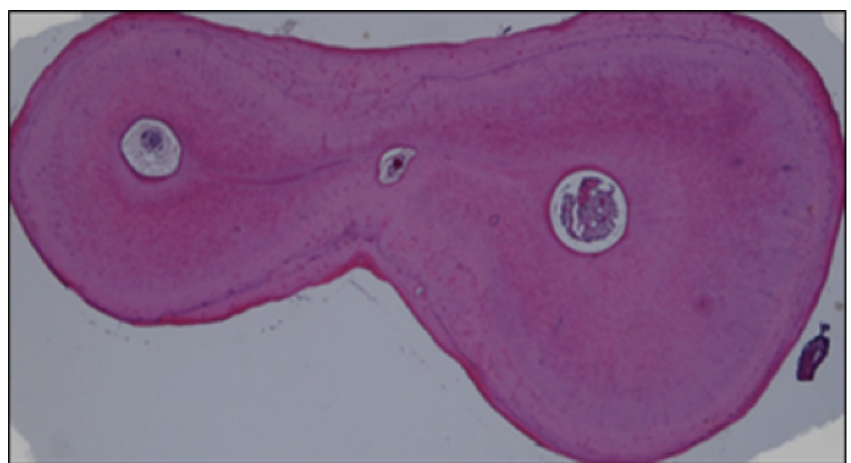

Resim 3: Çalışmamızda kullandığımız örnek dişler arasında Tip III isthmus varlığı

Tip III: Aralarında farkedilebilir derecede bir bağlantı olan üç kanal varlığı (Resim 3)

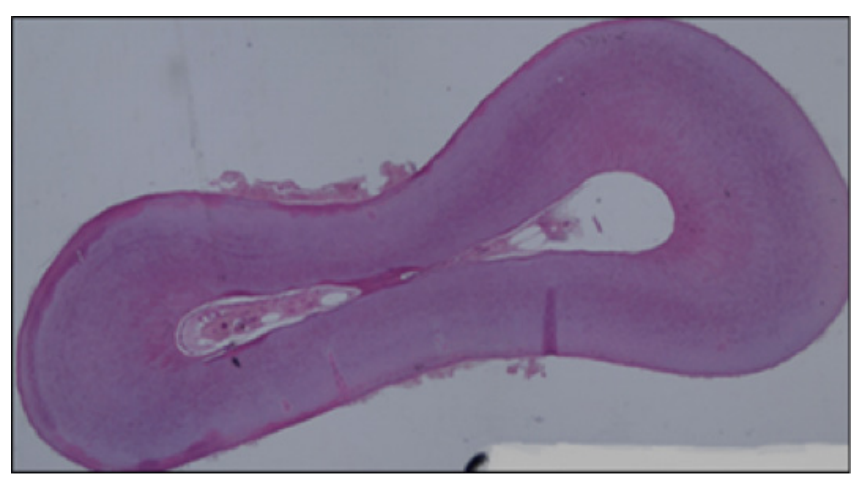

Resim 4: Çalışmamızda kullandığımız örnek dişler arasında Tip IV isthmus varlığı

Tip IV: Ana kanalın isthmusa uzantı yapması (Resim 4)

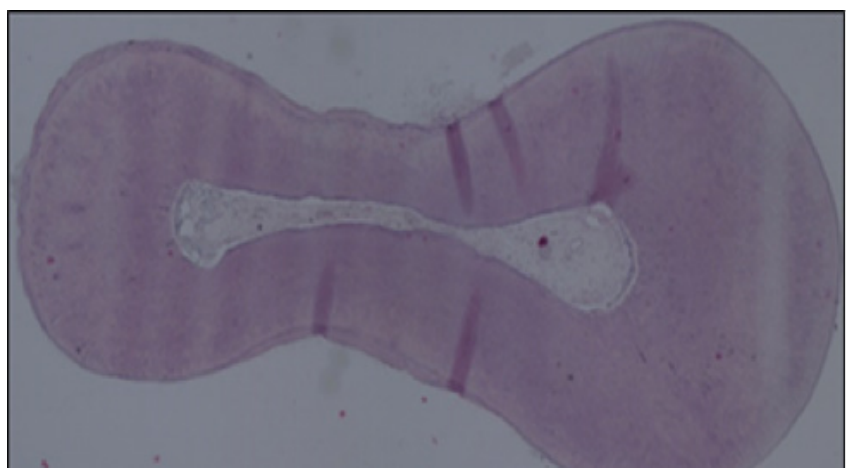

Resim 5: Çalışmamızda kullandığımız örnek dişler arasında Tip V isthmus varlığı

Tip V: Iki kanal arasında tam bir bağlantı veya koridorun varlığı (Resim 5) olan isthmuslardır.

\section{İstatistiksel değerlendirme}

Çalışmadaelde edilen bulgular değerlendirilirken, istatistiksel analizler NCSS (Number Cruncher Statistical System) 2007 Statistical Software (Utah, USA) paket programı kullanılmışır. Verilerin değerlendirilmesinde gruplar arası karşılaşıımalarda Kruskal Wallis testi kullanılmıştır. Sonuçlar, anlamlılk $p<0,05$ düzeyinde değerlendirilmiştir. 


\section{BULG ULAR}

Çalışmamızda elde edilen bulgular Tablo 1'de verilmiştir. Kullandığımız alt molar dişlerin mezial köklerinde isthmus görülme sıklığl; kuronal bölgede \%86, orta bölgede \%72 ve apikal bölgede \%84 oranındadır.

\section{TARTIŞMA}

Literatürde alt molar dişlerde bulunan isthmus tiplerinin incelendiği çalışmalarda 100 ile 330 arasında değişen sayıda diş kullanıldığı

\begin{tabular}{|c|c|c|}
\hline Bölge & $\begin{array}{c}\text { İsthmus } \\
\text { Tipi }\end{array}$ & \% \\
\hline \multirow{4}{*}{ Kuronal } & 1 & 14 \\
\cline { 2 - 3 } & 2 & 1 \\
\cline { 2 - 3 } & 4 & 15 \\
\cline { 2 - 3 } Orta & 5 & 70 \\
\cline { 2 - 3 } & 1 & 28 \\
\cline { 2 - 3 } & 2 & 4 \\
\cline { 2 - 3 } & 4 & 12 \\
\hline \multirow{4}{*}{ Apikal } & 5 & 56 \\
\cline { 2 - 3 } & 1 & 16 \\
\cline { 2 - 3 } & 2 & 5 \\
\cline { 2 - 3 } & 3 & 3 \\
\cline { 2 - 3 } & 4 & 14 \\
\hline \multirow{4}{*}{} & 5 & 62 \\
\hline
\end{tabular}

Tablo 1: Orneklerin kuronal, orta ve apikal kısımlarındaki isthmus tiplerinin oranları görülmektedir2, 20, 21. Bazl

çalışmalarda, çok az sayıda (20, 50 adet) diş kullanıldı̆̆ı da görülmüştür ${ }^{11,17}$. Bu nedenle yüz adet dişin böyle bir değerlendirme için yeterli bir sayı olabileceği kabul edilmiştir. İsthmusların tiplerine göre sınıflandırımasında Teixeira ve ark. ${ }^{17}$ Mehrvarzfar ve ark.'nın ${ }^{19}$ çalışmalarında olduğu gibi Hsu \& Kim'in ${ }^{16}$ sınıflaması kullanıımıştır.

Bulgularımıza göre, alt molar dişlerin mezial köklerinde isthmus görülme sıklığl; kuronal bölgede \%86, orta bölgede \%72 ve apikal bölgede \%84 oranındadır. Bu sonuçlar, Von $\mathrm{Arx}^{22}$ ve Gu ve ark. ${ }^{23}$ gibi araştırmacılar ile paralellik göstermektedir

Çalışmamızda incelenen örneklerin, kuronal bölgesinde rastlanan isthmusların \%70 oranında, orta bölgesinde \%56 oranında, apikal bölgesinde ise \%62 oranında Tip V olduğu gözlenmiştir. Bu bulgumuz da, Tip $V^{\prime}$ in en sık görülen isthmus tipi olduğunu bildiren pek çok çalışma tarafından desteklenmektedir 11,16,24.

Bizim bulgularımıza göre, apikal bölgede \%16 oranında Tip I, \%5 oranında Tip II, \%3 oranında Tip III, \%14 oranında Tip IV ve \%62 oranında Tip V isthmus bulunmuştur. Choudary \& Kiran ${ }^{18}$ çalışmasında, bizim bulgularımızdan farklı olarak, benzer dişlerin apikal bölgesinde, Tip I ve Tip III isthmusa rastlanmazken, \%26,6 oranında Tip ॥, \%41 oranında Tip IV ve \%32,3 oranında Tip V isthmus varlığı bildirmişlerdir. Teixeira ve ark. ${ }^{17}$ çalışmalarında, apikal bölgede \%54 oranında Tip I ve \%23 oranında Tip V isthmus varlığı tespit etmişlerdir. Sonuçlar arasındaki uyumsuzluğun, çalışmaların farklı toplumlar ve yaş gruplarına ait dişler üzerinde yapılmış olmasından kaynaklanabileceği düşünülmüştür

\section{SONUÇLAR}

Alt molar dişlerin mezial köklerinde gerçekleştirdiğimiz çalışmamızda isthmus görülme sıklığının çok yüksek olduğu saptanmıştır (\%86). Bu anatomik yapı Özellikle enfekte kök kanallarında kök kanalı tedavi başarısı yönünden ciddi bir tehdit oluşturmaktadır. Bulgularımız ışı̆̆ında, isthmus varlığı dikkate alındığında bu alanlara yönelik etkin yıkama ve şekilllendirme yöntemleri ile kök kanal tedavisi başarısı arasındaki ilişkinin önemi daha iyi anlaşılmaktadır. 


\section{KAYNAKLAR}

1. Skidmore AE, Bjørndal AM. Root canal morphology of the human mandibular first molar. Oral Surg Oral Med Oral Pathol. 1971; 32, 778-84.

2. VertucciFJ.Rootcanalanatomyofthehumanpermanent teeth. Oral Surg Oral Med Oral Pathol. 1984,58:589-99.

3. Dankner E, Friedman S, Stabholz A. Bilateral C shape configuration in maxillary first molars. I Endod. 1990;16:601-3.

4. Segura-Egea JJ, Jimenez-Pinzon A, Rios-Santos JV. Endodontic theraphy in a 3-rooted mandibular first molar importance of a thorough radiographic examination. J Can Dent Assoc. 2002;68:541-4.

5. 5. Jung IY, Seo MA, Fouad AF, Spangberg LSW, Lee SJ, Kim HJ, Kum KY. Apical anatomy in mesial and mesiobuccal roots of permanent first molars. J Endod. 2005:31:364-368.

6. Weine FS. Case report: three canals in the mesial root of a mandibular first molar(?). J Endod. 1982;8:517-20.

7. Weine FS, Pasiewicz RA, Rice RT. Canal configuration of the mandibular second molar using a clinically oriented in vitro method. J Endod. 1988;14:207-13.

8. Bram SM, FleisherR. Endodontic therapy in a mandibular second bicuspid with four canals. J Endod. 1991;17, 513-5.

9. Kartal N, Yanikoğlu F. The incidence of mandibular premolars with more than one root canal in a Turkish population. J Marmara Univ Dent Fac. 1992;1:203-10

10. Çalışkan MK, Pehlivan Y, SepetçioğluF, TürkünM, Tuncer SS. Root canal morphology of human permanent teeth in a Turkish population. J Endod. 1995;21:200-4.

11. Mannocci F, Peru M, Sherriff M, Cook R, Pitt Ford TR. The isthmuses of the mesial root of mandibular molars. a micro-computed tomographic study. Int Endod J. 2005,38:558-63

12. Matherne RP, Angelopoulos C, Kulild JC, Tira D. Use of cone-beam computed tomography to identify root canal systems in vitro. J Endod. 2008;34:87-9.

13. Lee JH, Kim KD, Lee JK, Park W, Jeong JS, Lee Y, Gu Y, Chang SW, Son WJ, Lee WC, Baek SH, Bae KS, Kum KY. Mesiobuccal root canal anatomy of Korean maxillary first and second molars by cone-beam computed tomography. Oral Surg Oral Med Oral Pathol Oral Radiol Endod. 2011:111:785-91.

14. Weine FS, Healey HJ, Gerstein H, Evanson, L. Canal configuration in the mesiobuccal root of the maxillary first molar and its endodontic significance. Oral Surg Oral Med Oral Pathol. 1969;28:419-25.

15. Pineda F, Kuttler Y. Mesiodistal and buccolingual roentgenographic investigation of 7,275 root canals. Oral Surg Oral Med Oral Pathol. 1972;33:101-10.
16. Hsu YY, Kim S. The resected root surface: the issue of canal isthmuses. Dent Clin North Am. 1997:41:52940.

17. Teixeira FB, Sano CL, Gomes BPFA, Zaia AA, Ferraz CCR, Souza-Filho FJ. A preliminary in vitro study of the incidence and position of the root canal isthmus and mandibular first molar. Int Endod J. 2003;36:276-80.

18. Choudary M, Kiran C. Isthmuses of the mesial root of mandibularfirst molar-Anspiralcomputed tomographic study. Endodotology. 2010,22:48-52.

19. Mehrvarzfar P, Akhlagi NM, Khodaei F, Shojaee G, Shirazi S. Evaluation of isthmus prevalence, location, and types in mesial roots of mandibular molars in the Iranian Population. Dent Res J. 2014;11:251-6.

20. Sert S, Aslanalp V. Tanalp J. Investigation of the root canal configurations of mandibular permanent teeth in the Turkish population. Int Endod J. 2004;37:494-9

21. Al-Qudah AA, Awawdeh LA. Root and canal morphology of mandibular first and second molar teeth in a Jordanian population. Int Endod J. 2009;42:775-84.

22. Von Arx T. Frequency and type of canal isthmuses in first molars detected by endoscopic inspection during periradicular surgery. Int Endod J. 2005,38:160-8.

23. Gu LS, Wei X, Ling JQ, Huang X. A microcomputed tomographic study of canal isthmuses in the mesial root of mandibular first molars in a Chinese population. J Endod. 2009;35:353-6.

24. Harris SP, Bowles WR, Fok A, McClanahan SB. An Anatomic Investigation of the Mandibular First Molar Using Micro-Computed Tomography. J Endod. 2013:39:1374-1378. 